\title{
IMAGO UNIVERSITATIS. LA IMAGEN DE LA UNIVERSIDAD DE SALAMANCA (27/11/2018-03/03/2019, HOSPEDERÍA FONSECA, SALAMANCA)
}

\author{
IMAGO UNIVERSITATIS. THE IMAGE OF THE \\ UNIVERSITY OF SALAMANCA (27/11/2018-03/03/2019, \\ HOSPEDERÍA FONSECA, SALAMANCA)
}

\author{
Elena Muñoz Gómez \\ (Universidad de Salamanca) \\ elenia@usal.es
}

Recibido: 4 de diciembre 2020 / Aceptado: 8 de febrero 2021

Tras la experiencia en 2013 con Miguel de Unamuno y la fotografía, Alberto Martín Expósito (Programación del VIII Centenario-USAL) y Miguel Ángel Jaramillo (Servicio de Archivos) plantearon el proyecto de Imago Universitatis: una reflexión visual acerca de la Universidad de Salamanca, que tomó cuerpo en la exposición inaugurada en marzo de 2018 en la salmantina Hospedería Fonseca [Fig.1]. Aquello fue el resultado de lo que, después, calificaron de largo trabajo en equipo, en el cual contaron con la colaboración de la catedrática de Historia del Arte, Lucía Lahoz, y la financiación de la Cooperación Territorial Europea. Se trataba de ofrecer, al hilo del VIII Centenario, un análisis de la identidad de la institución centrado en el proceso de construcción de su imagen a través de representaciones.

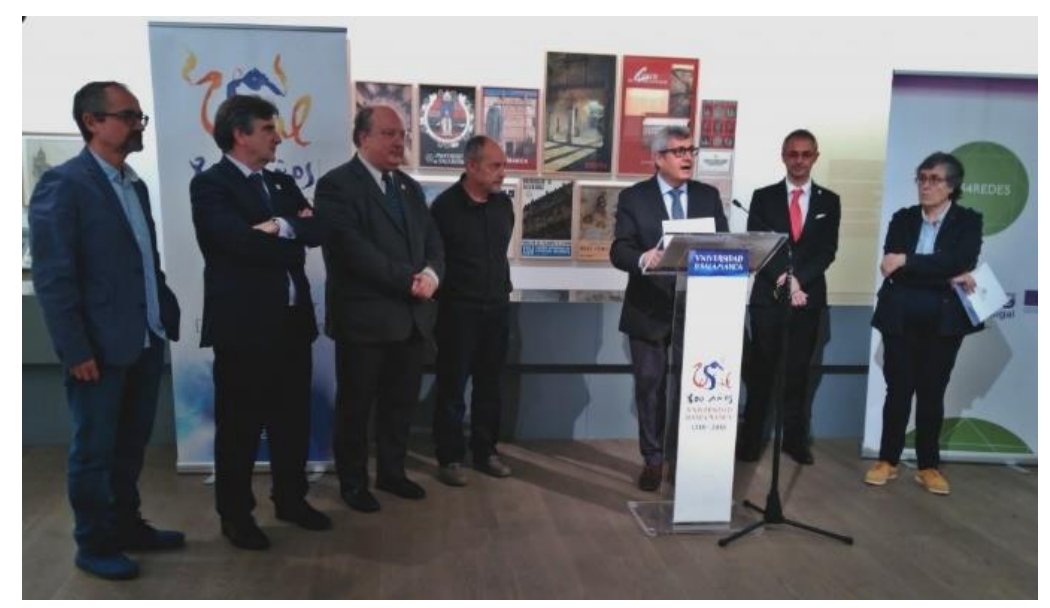

Fig.1: Fotografía de la inauguración en la Hospedería Fonseca. Salamanca.

La primera parte de la puesta en marcha del proyecto fue la selección de piezas en los fondos gráficos del archivo universitario, y la adquisición de documentos con los que, desde 2017, vienen ampliando este patrimonio de la USAL sobre sí misma. En la exposición, al final, se 
mostraron más de mil piezas, que no corresponden al total de documentos expuestos, porque algunos tuvieron que ser fragmentados en varios objetos, para desgranar discursos internos que no hubiesen podido visibilizarse de otra manera. Más de la mitad de esas piezas eran reproducciones; así no se alteraban los soportes originales al manipular y yuxtaponer sus imágenes en aquellas series. Evocaban una red de asociaciones, que no hubiese podido hacerse visible de otra manera. El montaje de reproducciones efectivamente transmitía una sensación monótona de serialidad y repetición: ejes temáticos y compositivos de la exposición.

Se dividía en cuatro salas dedicadas a analizar visualmente, con el apoyo de cartelas explicativas, el proceso iconológico que construye esta identidad institucional a lo largo de una historia escrita desde dentro. La primera, se dedicó a la génesis de los elementos representativos y fundacionales que iban a derivar en símbolos de la USAL. Se desplegaba una red de objetos generados por la universidad en sus albores, cuya utilidad los había dotado de una carga simbólica que pronto se inscribiría en la memoria social y topográfica. Fotografías de la estampación pétrea del sello universitario en diferentes arquitecturas, pendían al lado de un esquema donde se desglosaban los motivos que lo componen (sus agentes fundacionales: escudo papal, las armas de los reyes, y los estudiantes, rodeados por la inscripción que denomina esa imagen del Estudio). También se enmarcó allí la Bula de Alejandro IV que autoriza al Estudio a tener y utilizar el sello como símbolo autentificatorio, y la Concordia entre Ciudad y Universidad que regulaba en el siglo XV la entrada de vino a Salamanca, sellada con el que pudiera ser el modelo del sello monumental de Escuelas Menores. Otras fotografías acentuaban el carácter heráldico o decorativo del signo en otros edificios institucionales, o implícito en alguno de sus motivos desglosados en las fachadas del barrio universitario.

En la misma sala, otra pared se dedicó al análisis del elemento vertebrador de la muestra: la Fachada Rica, que incorpora el sello, tratada como clásico que marca el desarrollo posterior de la imagen de la USAL y ensombrece lo que había antes; así lo explicaba la comisaria Lahoz, aludiendo a una metáfora de Jose María Micó acerca de La Comedia. La sombra que proyecta esa fachada - decía la historiadora - nos hace difícil el apreciar la imagen arquitectónica que la precede. Lo que queda de ese edificio primitivo, definido en las Constituciones del Papa Luna, es el zaguán, como se deduce de la lápida fundacional y de la crítica de su historiografía, textos que determinan la retrospectiva del proceso de construcción de los símbolos, y por tanto se expusieron como parte de ese montaje 
anacrónico. La denominación de Portada Rica no haría alusión a la profusión figurativa del plateresco -proceso estilístico que se cuestiona- sino a la tapicería rica que se emula con la forma de fachada-telón y de cuyas funciones nutre la fachada su significado. Si el tapiz es un arte menor, era uno de los elementos mejor valorados en la sociedad que los ostentaba en los palacios para escenificar ritos donde se exhibía como objeto de magnificencia que señalaba la autoridad del poseedor, y actualizaba el saber sobre la Antigüedad en los entornos de los humanistas: factores culturales del diseño de esta fachada, desglosada en las fotografías. Se aprecia su lugar en la plaza cercada por edificios universitarios, donde se convierte en fachada interior - relacionada con madrasas islámicas- que incorpora un repostero: un tapiz histórico llevado a la escultura monumental para petrificar el rito de la ornamentación efímera ceremonial. Con más fotografías, que ilustran un movimiento topográfico, se explicó la gestación de esta imagen en función de la construcción de la Catedral Nueva, cuando el edificio universitario le dio la espalda girando su frente hacia el Patio de Escuelas. Según el discurso, en esta competencia institucional está la génesis de la Portada Rica, y también de la Biblioteca: otro símbolo que asume la identidad de una corporación consciente de su imagen pública: con ello habría de ganar estatus, según los documentos donde, además, se requiere para ello a los artífices Yusub y Abrahíme. Con este y otros motivos se puso en duda el tópico enfrentamiento de las culturas y cultos peninsulares, y se indicaba que la biblioteca era una arquitectura de autor. En una reconstrucción gráfica con fotografías, se aclaró cómo esta imagen arquitectónica condicionaba el diseño de una bóveda, de modelos clásicos e islámicos, pintada con el mural atribuido a Fernando Gallego: el Cielo de Salamanca: cúpula celeste de una arquitectura del saber, como escribió Marineo Sículo.

En la segunda sala se exponía la proyección impresa de estos símbolos, en grabados que, a partir del siglo XVIII, se sustituyen por fotografías en la prensa y otras ediciones vinculadas al estudio y difusión del patrimonio, y luego postales y guías para viajeros cada vez más numerosos, y turistas. Estos procesos de circulación ajenos a la institución, según explicaba Martín Expósito, son los que contribuyeron a difundir masivamente la imagen de la USAL, y conformaron una idea de universidad global, que promociona con sus símbolos la ciudad y la idea de universidad española. En esos libros y estampaciones, la institución aparece identificada por sus viejos símbolos u otro tipo de elementos representativos, que se analizaron en la Sala 3, dedicada a la utilización de personajes, desde Fray Luis de León hasta Unamuno, el rector que no cede su imagen a la USAL, sino que se apropia de ella -apuntaba Jaramillo. 
En la última sala se exponían piezas referidas a una consideración consciente de esta imagen a partir del VII Centenario, cuando se fijaron los signos de identidad que representan a una universidad decana española y europea recuperando el uso del sello, o el Vitor. Esta imagen -contaba Martín Expósito- fue la base de un reforzamiento del orden interno exteriorizado a través de la reproducción sistemática de los viejos signos en objetos ornamentales, como los que se expusieron en una última sala complementaria.

Para salir de la exposición había que retornar a la primera, y en su centro, dos sillares de piedra con los símbolos contrastaban frente a las reproducciones digitales, recordándonos que esta identidad necesita un material para promocionarse, aunque Rodríguez de la Flor, en el ensayo que se distribuyó dando título a la exposición, escribe que es lo inmaterial, lo que determina la estructura de lo material. A propósito de esto, la tercera fase del proyecto cuenta con el hecho de que la exposición también es reproducible, y de hecho ya está disponible la visita virtual que la réplica desde el día de clausura en Fonseca. La idea era que una continuase a la otra, como el catálogo, aún no editado, donde no se tratará de analizar las piezas sino los discursos que generaron los montajes en cada sala, la red de reproducciones seriadas que se aprecia ya en el cartel [Fig. 2] ${ }^{1}$.

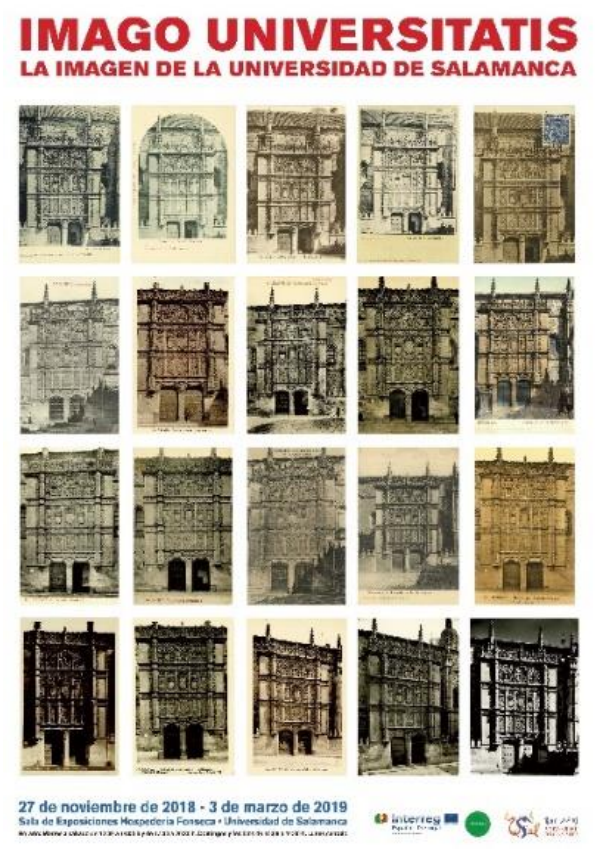

Fig. 2: Cartel de la muestra

\footnotetext{
${ }^{1}$ Enlace a la exposición virtual: Universidad de Salamanca (s.f.) Imago Universitatis. La imagen de la Universidad de Salamanca. Recuperado de: (http://sac.usal.es/images/stories/imago/); Soria, C. (s.f.). Universidad de Salamanca. Radio USAL. Inauguración de la exposición "Imago Universitatis. La imagen de la Universidad de Salamanca. Recuperado de: (https://radio.usal.es/noticia/inauguracion-de-la-exposicionimago-universitatis-la-imagen-de-la-universidad-de-salamanca/)
} 
A estos contenidos se irán sumando adquisiciones en un museo virtual de la USAL; comentaba Jaramillo: es la manera que tiene de aumentar su patrimonio y reconocerse a sí y sus fondos; de hacerse imagen. Algunos de los documentos expuestos salieron de organismos internos como la Biblioteca General y Patrimonio, o de colaboradores como Ayuntamiento, Archivo, Museo de Salamanca, o Filmoteca de Castilla y León y Fototeca del Instituto de Patrimonio Histórico y Cultual de España, además de la Biblioteca Nacional y otros como el Museo de la Universidad de Navarra o la Colección Fernández Rivero. Pero el grueso de la exposición se exhumó del archivo universitario: el fondo sobre el que la USAL construye esta imagen. Ello -apunta Jaramillo- lo sabían en el siglo XVII cuando construyeron un nuevo mueble de archivo en cuyas puertas aparecen aquellos signos de identidad; estas ilustraron el tríptico de la exposición y protagonizaron las salas junto al sello y la fachada, como documento figurativo -explicaba Lahoz- de la labor docente en un aula en la que el dictado sustituye a la memoria y la oralidad [Fig.3].

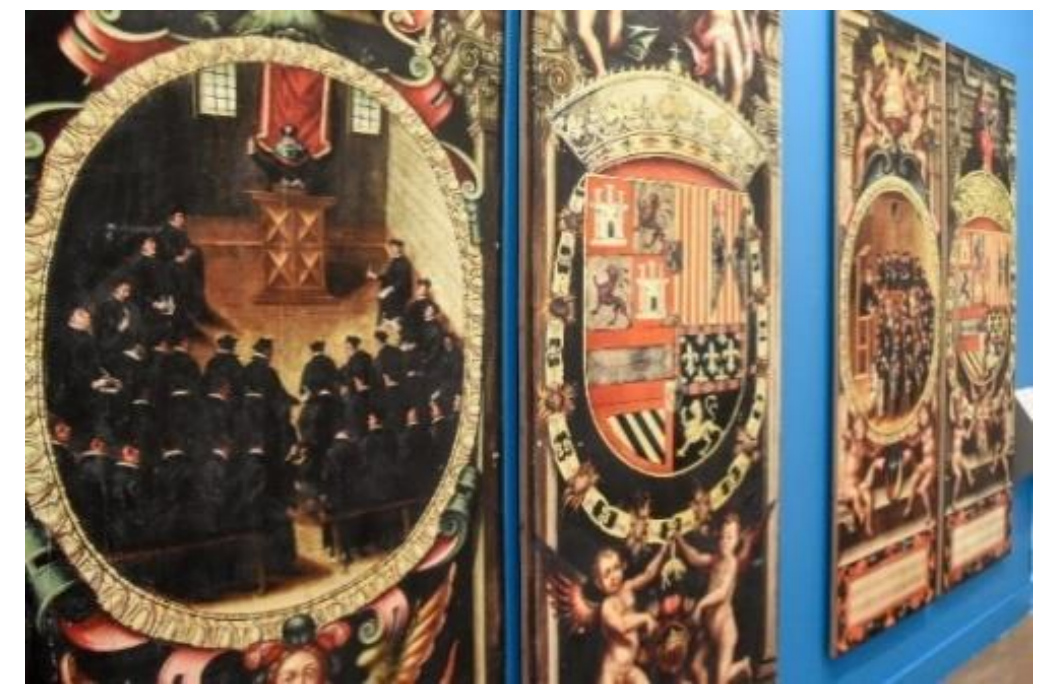

Fig. 3: Montaje de las reproducciones fotográficas de las puertas del archivo universitario.

La exposición, al modo wagburiano, yuxtaponiendo reproducciones, subraya la función de la copia en el trabajo museístico e historiográfico. Mientras el discurso homenajea la identidad histórica, el montaje desvela su construcción en representaciones. Se trata de una imagen ligada a las artes de reproducción, como el tapiz, que se petrifica y se instaura como símbolo a través de su reproducción en nuevos procesos mecánicos y digitales. La escenificación de uno mismo en un autohomenaje es típica de instituciones en aniversarios, decía Jaramillo, porque les permite reconocerse y publicitarse, en un juego de espejos - en palabras de Expósito - que refleja la corporación, y a los que han tomado y trasladado su cuerpo de imágenes. El proyecto es una demostración de autoconciencia, de que el saber a cerca de la 
identidad propia se ha convertido en parte de la misma y de cómo esta adquiere así el carácter reflexivo que la enfrenta al peligro de abismarse.

\section{Recursos bibliográficos}

Soria, C. (s.f.). Universidad de Salamanca. Radio USAL. Inauguración de la exposición "Imago Universitatis. La imagen de la Universidad de Salamanca. Recuperado de: (https://radio.usal.es/noticia/inauguracion-de-la-exposicion-imago-universitatis-la-imagende-la-universidad-de-salamanca/)

Universidad de Salamanca (s.f.) Imago Universitatis. La imagen de la Universidad de Salamanca. Recuperado de: (http://sac.usal.es/images/stories/imago/). 